\title{
PRONUNCIAMIENTO DE LA CORTE CONSTITUCIONAL MEDIANTE LA SENTENCIA T-133/04 SOBRE LA AFECTACION DE LA VIDA E INTEGRIDAD PERSONAL POR LA VIOLENCIA INTRAFAMILIAR GENERADA POR EL ALCOHOLISMO Y LA DROGADICCION.
}

\author{
Autores: Luis Carlos Pimienta Henao ${ }^{1}$ \\ Correspondencia: Ipimientah18@curnvirtual.edu.co
}

\section{RESUMEN}

La violencia intrafamiliar generada por el alcoholismo y la drogadicción es un fenómeno que mina a la sociedad colombiana, que desgasta sus cimientos más fuertes y que vulnera los principios constitucionales como la vida, la integridad personal y la paz, cuyos derechos no pueden pasar por alto las políticas estatales que pretenden mejorar las condiciones de vida de sus ciudadanos ya que estos rebosan los límites del delito penal y se expanden en sobremanera para ubicarse en otros tipos penales especiales que concursan con el mismo para acrecentar la amonestación jurídica que en el campo penal se concreta en la imposición de una pena o una sanción para el transgresor.

En esta investigación de línea jurisprudencial se analizan las sentencias involucradas con esta situación, para definir un concepto de derecho constitucional utilizada en la solución de estos casos, y que en su conjunto integran la línea jurisprudencial cuyo perímetro profundo es posible localizar el fundamento explicito de la norma legal indicada.

\section{Palabras clave}

Afectación, Vida, Violencia intrafamiliar, Alcohismo, Drogadicción

\begin{abstract}
The violence intrafamiliar generated by the alcoholism and the drug addiction is a phenomenon that it mines to the Colombian company, which spoils his stronger foundations and which damages the constitutional beginning as the life, the personal integrity and the peace, which rights cannot overlook the state policies that try to improve the living conditions of his citizens since these overflow the limits of the criminal offence and expand in exceedingly to be located in other penal special types that compete with the same one to increase the juridical admonition that in the penal field makes concrete in the imposition of a sorrow or a sanction for the transgressor.

In this investigation of juriprudential line there are analyzed the judgments involved with this situation, to define a concept of constitutional law used in the solution of these cases, and that in his set integrate the juriprudential line which deep perimeter is possible to locate the explicit foundation of the legal indicated norm.
\end{abstract}

\footnotetext{
${ }^{1}$ Abogado. Litigante
} 


\section{Keywords}

Affectation, Life, Violence intrafamiliar, Alcohismo, Drogadiccíon

\section{INTRODUCCIÓN}

Esta investigación de línea jurisprudencial ha sido enmarcada resumidamente al respeto a la vida, la integridad personal y a la paz, cuya normatividad es elevada al rango constitucional, que además de indicar las diversas inquietudes que puede proporcionar el título de este trabajo también dará espacio a la identificación de unas normas de desarrollo sentencial de la Corte Constitucional Colombiana relacionadas con el tema; el cual se refiere a la violencia intrafamiliar ocasionado por el alcoholismo y la drogadicción; fenómenos que puede tener un tratamiento que puede pasar desapercibido, sin importancia, algo común en la vida diaria, pero es más bien todo lo contrario, va mucho más allá, con unos resultados sancionatorios o penales asombrosos e impactantes como el rechazo social que genera y con el traumático físico-sicológico que sobre sus víctimas produce.

No es para menos, el abuso del alcohol y las drogas alucinógenas entre los miembros de una misma familia contiene tanta gravedad y fatalidad, que rebosan los límites propios del delito de la violencia intrafamiliar y se expanden sobremanera para ubicarse en otros tipos penales especiales que concursan con el mismo para acrecentar la amonestación jurídica que en el campo penal se concreta en la imposición de una pena o sanción para el transgresor.

Desde este punto de vista es muy claro que todos los miembros de una familia azotados por el alcoholismo y la drogadicción se ven afectados con graves conflictos internos, desde palabras agresivas, ataques sicológicos y físicos que pueden generar lesiones graves o la misma muerte y por consiguiente problemas jurídicos penales; por lo tanto los integrantes de la familia cuando se ven 
Vol. 6, No. 1 Diciembre de 2014 pp. $89-120$

amenazados en su integridad física personal y que la situación se salió de control para la persona alcohólica o drogadicta acuden a los estrados judiciales.

Por consiguiente, los veredictos de los altos Estrados judiciales con relación a este tema manifiestan un constante progreso evolutivo en el que poco a poco se van perfilando sus reales límites hasta alcanzar la jerarquía que hoy ostenta. Las resoluciones que hoy son de conocimiento público, expresadas en Sentencias referidas a este fenómeno y que integran una línea jurisprudencial definida, fueron objeto de un minucioso análisis por parte de los investigadores.

\section{MATERIALES Y MÉTODOS}

Esta investigación es de método dogmatico jurídico, ya que se logra encontrar por una parte la construcción de una línea jurisprudencial a partir de las diferentes posturas o Sentencias manifestadas por la Corte Constitucional respecto a la afectación de la vida e integridad personal por la violencia intrafamiliar generada por el alcoholismo y la drogadicción.

\section{RESULTADOS Y DISCUSIÓN}

\section{Planteamiento del Problema Jurídico}

La Constitución Política Colombiana en el Artículo 12 señala que "nadie será sometido a desaparición forzada, a torturas ni a tratos o penas crueles, inhumanos o degradantes" (2001). A su vez existen otras leyes u ordenanzas como las emanadas en el Código Penal en el Artículo 229 que expresa "El que maltrate física o sicológicamente a cualquier miembro de su núcleo familiar, incurrirá, siempre que la conducta no constituya delito sancionado con pena mayor, en prisión de cuatro (4) a ocho (8) años". (Ley 599 de 2000). A ello agrega el mismo Código, "la pena se aumentará de la mitad a las tres cuartas partes cuando el maltrato recaiga sobre un menor" (Ley 599 de 2000). 
Con la enunciación de las normas anteriores se refleja el problema de la violencia intrafamiliar base del tema, la cual, con su intensidad de peligrosidad e impacto en la sociedad y la vida familiar se incrementa con el alcoholismo y la drogadicción.

Estos estereotipos de adicciones sean generados por el licor o las drogas alucinógenas han ocasionado problemas tanto en la vida familiar y social por el grado de agresividad y perdida de la realidad de los transgresores adictos, el cual vulnera el derecho a la vida, a la integridad personal y porque no decirlo también, a la paz, con lo que peligran los derechos fundamentales de las víctimas. Estas a su vez, emprenden demandas o procesos judiciales y muchas de ellas han alcanzado a las Altas Cortes en búsqueda de algún mecanismo de protección a sus derechos constitucionales.

\section{Punto Arquimédico}

- Sentencia T-529/92 (Derecho a la Vida e Integridad Personal). Considerada como la Sentencia fundadora de la línea porque fue la primera en la que se realizó un pronunciamiento sobre el tema de las Altas Cortes, al indicar que:

El respeto a la vida y a la integridad física de los demás, en un sentido moral y jurídicamente extenso que no se reduce sólo a la prevención policiva o a la represión penal del agresor, comporta el deber de no maltratar, ni ofender, ni torturar, ni amenazar a las personas, mucho menos a aquella con quien se comparten la unión doméstica de procreación y desarrollo de los hijos y de la familia, y la promesa de mutuo fomento material y espiritual. (Colombia. Corte Constitucional, 1992) 
Vol. 6, No. 1 Diciembre de 2014 pp. $89-120$

\section{Telaraña e Ingeniería de reversa}

\begin{tabular}{|c|c|c|c|c|c|c|c|}
\hline \multicolumn{8}{|c|}{ T-133/04 } \\
\hline T-529/92 & T-487/94 & T-552/94 & T-421/96 & $\mathrm{T}-608 / 01$ & T-789/01 & $\mathrm{T}-1325 / 01$ & T-684/02 \\
\hline & T-529/92 & T-487/94 & T-529/92 & T-003/92 & T-529/92 & T-1204/00 & T-696/01 \\
\hline & \multirow{9}{*}{ C-371/94 } & C-587/92 & T-487/94 & T-161/93 & T-233/94 & T-489/98 & T-533/92 \\
\hline & & T-529/92 & T-552/94 & \multirow{8}{*}{ T-014/94 } & T-531/97 & SU-480/97 & T-426/92 \\
\hline & & T-264/93 & & & T-503-99 & SU-819/99 & T-046/97 \\
\hline & & & & & T-372-96 & $\mathrm{T}-114 / 97$ & \multirow[t]{6}{*}{ T-1330/01 } \\
\hline & & & & & $\mathrm{T}-421 / 96$ & T-640/97 & \\
\hline & & & & & T-707/99 & T-784/98 & \\
\hline & & & & & \multirow[t]{3}{*}{ T-277/99 } & SU-111/97 & \\
\hline & & & & & & T-796 /98 & \\
\hline & & & & & & T-1204 /00 & \\
\hline
\end{tabular}

\section{Puntos nodales jurisprudenciales}

T-529/92 = 5 Veces (Sentencia Derecho a la Vida e Integridad Personal)

T-487/94 = 3 Veces (Acción de Tutela contra el Cónyuge e indefensión)

T-552/94 = 2 Veces (Derecho a la Integridad Personal/ Vulneración Derecho a la Vida)

T-421/96 = 2 Veces (Violencia Familiar / Maltrato Intrafamiliar)

\section{Sentencia confirmadora}

¿Existe el amparo constitucional como mecanismo de protección para la afectación de la vida e integridad personal por la violencia intrafamilie generada por el alcoholismo y la drogadicción?

\begin{tabular}{c|c}
\hline SI & NO \\
\hline T-529/92 & \\
T-487/94 & \\
T-552/94 & \\
T-421/96 & \\
T-133/04 & \\
\hline
\end{tabular}


Se puede analizar que la Corte Constitucional ha mantenido el amparo constitucional en todas las Sentencias que ha fallado a favor de la protección de la vida, la integridad personal y la paz que es a nivel constitucional, y a su vez ha juzgado la violencia intrafamiliar, aunque la sala suprema solo se pronuncia en la Sentencia T-133/04 cuando la violencia familiar es generada por efectos del alcohol y las drogas alucinógenas.

\section{Análisis estático jurisprudencial}

\section{- Sentencia T-133/04}

Hechos

La Sentencia se basa en la historia de un hombre que agrede verbalmente a su madre y de igual manera a su tía, porque éste exige dinero y no lo complacen. Este hombre amenaza con hacerles daño y también arremete contra la vivienda. Se trata de un señor Ilamado Guillermo Marmolejo García; es un hombre de 48 años de edad, con domicilio en la ciudad de Cali, el cual tiene problemas con el alcohol y las drogas. Cuando se encuentra bajo los efectos del alcohol y de las drogas llega a la casa de la madre y la tía para exigirles que le entreguen dinero, cabe anotar que la madre y la tía son señoras de avanzada edad. Como estas no le cumplen sus caprichos económicos, éste comete actos de violencia contra la casa, rompiendo ventanas y agrediendo verbalmente a las señoras.

Al agresor ya se le había demandado e impetrado una tutela con anterioridad ante el Juez de primera instancia, en el Juzgado Tercero Penal Municipal de Cali.

La demandante solicita protección constitucional y la adopción de medidas orientadas a ese propósito, en este caso se refiere a la acción de tutela, la cual como es sabido es un mecanismo efectivo y rápido al alcance de cualquier ciudadano con el fin de proteger los derechos fundamentales. 


\section{Ratio decidendi}

Como es de entender el Ratio Decidendi hace referencia a aquellos argumentos de la Corte Constitucional en que la parte considerativa de una Sentencia o Resolución judicial que constituyen la base de la decisión acerca de la materia sometida a su conocimiento, además tiene carácter vinculante y por lo tanto obligan a los tribunales inferiores cuando deben resolver casos similares, en este caso la Ratio Decidendi.

Antes de la Ley 294 de 1996, esta Corporación admitió que el maltrato físico o moral al interior de la familia comporta una situación de indefensión para las víctimas (Sentencia T-529-92 y Sentencia T-487-94) y reconoció que en razón del maltrato pueden vulnerarse los derechos a la vida y a la integridad personal de aquellos miembros de la familia que son sometidos por la violencia física o moral (Sentencia T-529-92 y Sentencia T-552-94). De allí que en esos supuestos, sin desconocer el alcance de instituciones propias del derecho de familia, penal o policivo, aceptó la procedencia del amparo constitucional para proteger los derechos fundamentales de las víctimas de esa modalidad de violencia.

No obstante en lo expuesto y luego de la expedición de la Ley 294 de 1996, mediante la cual se prevé un tratamiento integral de las diferentes modalidades de violencia en la familia, esta Corporación afirmó la improcedencia de la acción de tutela para amparar los derechos fundamentales vulnerados o puestos en peligro con ocasión de la violencia intrafamiliar (Colombia. Corte Constitucional, 1996) por cuanto ella establece en la Sentencia T-421-96):

Claros medios de defensa judicial, cuyo objeto consiste específicamente en la protección inmediata, mediante trámites sumarios y expeditos, de los derechos fundamentales que puedan ser vulnerados en tales situaciones. De esta manera, la acción de tutela, eminentemente residual y subsidiaria, 
Vol. 6, No. 1 Diciembre de 2014 pp. $89-120$

pierde su razón de ser y en consecuencia no debe ser admitida en estos casos. (1996).

También la corte reflexiona de acuerdo a la Constitución colombiana, el derecho de los ciudadanos y la responsabilidad de los jueces respecto a las tutelas.

Una de las innovaciones más importantes de la Constitución de 1991 fue la Acción de Tutela pues a través de éste mecanismo los ciudadanos acceden a los jueces, mediante un procedimiento preferente y sumario, con miras a la protección de los derechos fundamentales. Para la eficacia de ese mecanismo de protección, la ley consagró sanciones para las personas que incumplan las órdenes impartidas por los jueces que conocen de él. Por ello, el Artículo 52 del Decreto 2591 de 1991 dispone que esa sanción consistirá en arresto hasta de seis meses y multa hasta de 20 salarios mínimos legales mensuales, salvo que se hubiese señalado una consecuencia distinta y sin perjuicio de las sanciones penales a que hubiere lugar.

La Alta Corte indica que se cometió un acto antijurídico con el agresor alcohólico drogadicto por parte del juez de primera instancia, del Juzgado Tercero Penal Municipal de Cali, según:

- Desconoció el principio de buena fe al presumir el posterior incumplimiento del accionado.

- Determinó la sanción sin previamente haber establecido la responsabilidad del accionado en el futuro incumplimiento.

- Ordenó su internación en el anexo siquiátrico de una cárcel cuando, de conformidad con la ley, lo único que procede es el arresto y la multa. 
El Obiter Dictum hace referencia a aquellos alegatos expuestos en la parte considerativa de una Sentencia o resolución judicial que corroboran la decisión principal, pero carecen de poder vinculante, pues su naturaleza es meramente complementaria.

Es el mismo juez quien opina o da su punto de vista jurídico acerca de un tema específico, y es esta opinión la que más tarde se puede tomar como válida para el uso en un proceso judicial, pero nunca tendrá valor de ley.

En la sentencia citada el juez invoca un punto de vista jurídico, el cual, se halla en la Sentencia T-1325/01, para su veredicto y conocimiento del tema. Esta es de utilidad y orientación para el caso referente al alcoholismo:

el alcoholismo presenta, desde el punto de vista jurídico, varias características relevantes y concurrentes: i) se trata de una afección que es el resultado del deseo repetido de quien consume alcohol, es decir, el alcoholismo no surge instantáneamente sino que su desarrollo supone una conducta continuada en el tiempo; ii) el consumo de alcohol puede generar cambios profundos en el comportamiento de la persona -a diferencia de otras adicciones como el tabaco- que pueden afectar las relaciones interpersonales del alcohólico y amenazar derechos de terceras personas; iii) superar el alcoholismo requiere del concurso decidido y constante de la voluntad de la persona que consume alcohol -aunque dicha voluntad podría ser insuficiente-

Y también, a su vez utiliza el punto de vista jurídico respecto a la drogadicción basada en la Sentencia T-684/02:

el estado de drogadicción crónica debe ser atendido por el sistema de seguridad social en salud. Bien sea por el régimen subsidiado o el 
contributivo e inclusive por las entidades públicas o privadas que tienen contratos con el Estado para la atención de los vinculados al sistema en caso de que se demuestre la necesidad inminente del tratamiento y la incapacidad económica del afectado para cubrirlo. (Colombia. Corte Constitucional, 2002)

\section{Decisión de la Sentencia}

La Corte Constitucional manifiesta su veredicto de acuerdo a sus valoraciones conforme a las leyes colombianas, a sus puntos de vista jurídicos y experiencias en las diversas experiencias y resultados de otras áreas, el cual, restablece los derechos constitucionales a las víctimas, modifica la Sentencia proferida por el Juzgado Tercero Penal Municipal de Cali e impone unas sanciones y vigilancia al agresor:

Primero. Modificar el numeral primero de la parte resolutiva de la Sentencia proferida el 22 de septiembre de 2003 por el Juzgado Tercero Penal Municipal de Cali, en los siguientes términos: a) conceder, como mecanismo transitorio de protección, la tutela de los derechos fundamentales a la vida y la integridad personal los afectados, b) ordenar al agresor abstenerse de ejecutar actos de violencia física o moral en contra de los familiares afectados, c) ordenar al Comandante de la Estación del barrio El Lido de Cali, ejercer vigilancia sobre la conducta del agresor para la protección de los derechos a la vida y a la integridad personal de Esperanza Mejía Arias, d) confiar al Juzgado Tercero Penal Municipal de Cali velar por el cumplimiento de lo ordenado en esta sentencia, f) solicitarle a la Defensoría del Pueblo, Regional Cali, que le preste a la actora la asistencia jurídica que requiere para el ejercicio de los mecanismos legales de protección contra los actos de violencia emprendidos por Guillermo Marmolejo Mejía.

Segundo. La protección dispuesta permanecerá vigente sólo durante el término que la autoridad competente utilice para decidir de fondo sobre la acción 
que la afectada instaure, con base en la Ley 294 de 1996, en los 30 días siguientes a la notificación de este pronunciamiento y con la asistencia de la Defensoría del Pueblo, Regional Cali.

Tercero. Solicitarle a la Secretaría de Salud del Valle del Cauca que disponga lo necesario para que a Guillermo Marmolejo Mejía se le preste el tratamiento médico que requiere en razón del alcoholismo y la drogadicción que le afectan.

Cuarto. Revocar el numeral segundo de la parte resolutiva de la Sentencia proferida por el Juzgado Tercero Penal Municipal de Cali.

Quinto. Dese cumplimiento a lo dispuesto en el Artículo 36 del Decreto 2591 de 1991.

\section{- Sentencia T-529/92}

Hechos

La señora Blanca Cecilia Castro López, presentó acción de tutela contra su esposo de nombre Gustavo Cárdenas ya que este le está violando el derecho a la vida y a la integridad física, a la paz doméstica y a la intimidad familiar, por los continuos golpes y amenazas que éste le viene sometiendo a su cónyuge.

La demandante argumenta que su esposo la amenaza y la golpea, que mantiene permanentes actitudes de violencia física, de amenazas y de improperios que se dan tanto en público como en privado. Informa que al año de estar casados el esposo inicio con la violencia, los ultrajes y los malos tratos, esto llevo a convertirse en lesiones personales; también manifiesta que no obstante a la violencia física a la cual es sometida, también ha sido objeto de ultrajes 


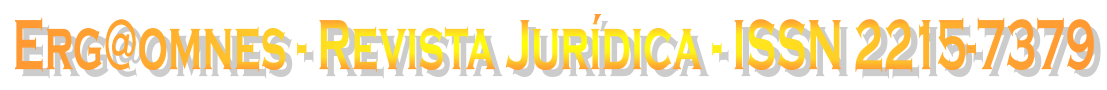

Vol. 6, No. 1 Diciembre de 2014 pp. $89-120$

verbales, golpes y heridas físicas durante varios años, y a la fecha de la demanda no cesan.

\section{Ratio Decidendi.}

Como se indicó anteriormente la Ratio Decidendi hace referencia a aquellos argumentos de la Corte Constitucional en que la parte considerativa de una Sentencia o resolución judicial que constituyen la base de la decisión acerca de la materia sometida a su conocimiento, además tiene carácter vinculante y por lo tanto obligan a los tribunales inferiores cuando deben resolver casos similares, en este caso la Ratio Decidendi:

La Corte se pronuncia y realiza cuatro consideraciones:

a) La Competencia. Esta Sala de la Corte Constitucional es competente para conocer de la revisión de la Sentencia de la referencia, en atención a lo dispuesto por los Artículos 86, inciso tercero y 241, numeral 9o. de la Constitución Política, en concordancia con los Artículos 33, 34, 35 y 236 del Decreto 2591 de 1991; además, este examen se hace por virtud de la selección que de dicho acto practicó la Sala correspondiente y del reparto que se verificó en la forma señalada por el Reglamento de esta Corporación.

b) La Materia Objeto de las Actuaciones. En primer término encuentra la Sala que la peticionaria de modo expreso solicita por virtud del ejercicio de la Acción de Tutela que consagra el Artículo 86 de la Carta Política y que reglamenta el Decreto 2591 de 1991, la protección del Derecho Constitucional a la Vida y a la Integridad Física que se garantiza con el Artículo 11 de la Carta Fundamental; de modo complementario, la peticionaria invoca la protección de otros derechos de carácter constitucional como son el Derecho a la Intimidad Familiar y a la Paz Doméstica consagrados en los Artículos 42 y 43 de la Carta Política. 
c) Las Declaraciones y los Testimonios que obran en el expediente.

Como se advirtió más arriba, dentro del expediente existe constancia de dos testimonios válidamente dipuestos ante autoridad judicial competente, en los que se prueba debidamente que el Señor Gustavo Cárdenas, esposo de la peticionaria, da malos tratos a su esposa, que la ofende de modo indigno y descomedido, que la trata con golpes inhumanos de manera recurrente y habitual, poniendo en peligro su vida y atentando contra su integridad física, produciéndole, además, desmayos y lesiones faciales.

\section{Obiter Dictum}

La Acción de Tutela, consagrada en el Artículo 86 de la Constitución Nacional y el Derecho a la Vida y a la Integridad Personal.

Ahora bien, para definir otro de los fundamentos de esta providencia, esta Sala, en acatamiento de su jurisprudencia reiterada en fallos anteriores, estima que la Acción de Tutela está prevista en el Artículo 86 de la Carta Fundamental como un mecanismo procesal específico y directo que tiene por objeto la eficaz protección concreta e inmediata de los derechos constitucionales fundamentales, en una determinada situación jurídica, cuando éstos sean violados o se presente amenaza de su violación y cuando sean reclamados de modo concreto y específico, no obstante que en su formulación concurran otras hipótesis como el reclamo de protección judicial de derechos de otra naturaleza y categoría.

El Obiter Dictum hace referencia a aquellos alegatos expuestos en la parte considerativa de una Sentencia o resolución judicial que corroboran la decisión principal, pero carecen de poder vinculante, pues su naturaleza es meramente complementaria. 
Además, el Tribunal estima que el derecho a la Paz Doméstica no está consagrado como fundamental, pues, en su concepto éste debe considerarse como el entendimiento y la armonía que debe reinar entre quienes han constituido una familia legítima por medio de las nupcias, cuyas relaciones deben basarse en el respeto recíproco y en la igualdad de derechos y deberes, tal como prevé el Artículo 42 de la Constitución Nacional. Estima el Despacho judicial que la protección de la paz familiar o conyugal no ocasiona la aplicación de la tutela sino de otros mecanismos legales como los que conducen a la separación de cuerpos y del divorcio. También, señala que la "Intimidad Familiar " de la que trata el Artículo 15 de la Constitución Nacional, protege a todo el núcleo familiar, no excluye a ninguno de sus miembros y no puede conducir a la expulsión de éstos del lugar donde habita y reside la familia.

\section{Decisión de la Sentencia}

La Corte de la Sala Constitucional da a conocer su veredicto conforme a sus valoraciones de las leyes colombianas, a sus puntos de vista jurídicos y experiencias en las diversas experiencias y resultados de otras áreas, el cual, restablece los derechos constitucionales a las víctimas, revoca la Sentencia proferida por el Tribunal Superior de Pereira e impone unas sanciones y vigilancia al agresor:

Primero. REVOCAR la Sentencia proferida por el Honorable Tribunal Superior de Pereira -Sala de Familia- en la cual se decidió sobre la solicitud de tutela presentada por la señora Blanca Cecilia Castro López, en el caso de la conducta de su esposo Gustavo Cárdenas.

Segundo. TUTELAR los Derechos Constitucionales a la Vida y a la Integridad Personal que reclama por medio de su representante judicial, la ciudadana Blanca Cecilia Castro López contra su esposo Gustavo Cárdenas. 
Tercero. Ordenar que las autoridades de policía del Permanente Sur de la ciudad de Pereira, ejerzan dentro de sus competencias legales vigilancia permanente sobre la conducta del citado Gustavo Cárdenas, contra quien se adelantó la Acción de Tutela de la referencia para la efectiva protección de los derechos constitucionales a la vida y a la integridad personal de la Señora Blanca Cecilia Castro López. Igualmente dichas autoridades deben prestar la mayor y eficaz atención a las solicitudes de apoyo de la Señora Castro López ante la conducta agresiva de su esposo.

Cuarto. ORDENAR a las autoridades competentes del Instituto Colombiano de Bienestar Familiar en la Regional Risaralda que adelanten todas las medidas de protección a los derechos constitucionales a la Vida y a la Integridad Personal de la Señora Blanca Cecilia Castro López, ante la conducta de su esposo y cuyas condiciones personales aparecen referenciadas en el expediente.

Quinto. Ordenar que para los efectos que sean del caso, por el Honorable Tribunal Superior de Pereira se remita copia de esta Sentencia y de todo el expediente a los despachos judiciales donde se adelantan las acciones penales y de familia en las que son partes blanca Cecilia Castro López y Gustavo Cárdenas.

Sexto. El Tribunal Superior de Pereira informará a esta Corte Constitucional sobre el cumplimiento de lo ordenado en la presente Sentencia.

Séptimo. Comuníquese la presente decisión al Despacho Judicial de origen para que sea notificada conforme lo dispone el Artículo 36 del Decreto 2591 de 1991.

- Sentencia T- 487/94

Hechos 
La Señora María Esther Moreno Ramírez instauró acción de tutela contra su compañero permanente, Manuel López, ya que este constantemente la golpea y la ultraja; ésta solicita que sus derechos fundamentales sean protegidos e indica la demandante que su compañero la viene intratando, le pega y la ultraja. Lo máximo que dura sin tratarla mal, son apenas dos meses, lo contrario son agresiones son constantes.

También manifiesta que el señor no le cumple con las obligaciones alimentarias. Cuando sale de la casa permanece ausente hasta por semanas y cuando vuelve le falta el respeto argumentado que tiene otras mujeres fuera del hogar.

En su declaración informa que el señor maltrata a sus hijos comunes y a las hijas de ella, el no permite que las hijas de la demandante la visiten. Indica que uno de sus hijos tuvo que abandonar la escuela.

\section{Ratio Decidendi}

Como se viene indicando continuamente en las Sentencias analizadas con anterioridad, la Ratio Decidendi hace referencia a aquellos argumentos de la Corte Constitucional en que la parte considerativa de una Sentencia o Resolución judicial que constituyen la base de la decisión acerca de la materia sometida a su conocimiento, además tiene carácter vinculante y por lo tanto obligan a los tribunales inferiores cuando deben resolver casos similares, en este caso la Ratio Decidendi.

La Corte Suprema hace referencia al acceso a la Tutela como medio de protección constitucional. 
La acción de Tutela procede contra particulares, entre otros casos, cuando quien la intenta se halla en estado de indefensión respecto de la persona a la cual sindica de vulnerar o amenazar sus derechos fundamentales de acuerdo con lo que estipula el Artículo 86 y 42 de la Constitución (Colombia. Asamblea Nacional Constituyente, 1991) y el numeral 9, del Decreto 2591 de 1991. (Colombia. Congreso de la República, 1991)

Al igual la Corte Constitucional invoca la protección de la familia en los siguientes términos: la familia, tanto la constituida a partir del matrimonio como la nacida de vínculos naturales por la voluntad responsable de conformarla, merece especial protección constitucional, pues es considerada institución básica y núcleo fundamental de la sociedad (Artículos 5 y 42 de la Constitución Nacional, 1991).

La Sala de la Corte manifiesta las actividades que ejercen los entes policiales, el cual, es de carácter administrativo y por ningún modo judicial, por lo tanto el servicio policivo no puede realizar ninguna sanción contra agresores que generen violencia dentro del seno familiar.

Como las acciones policivas no son judiciales, sino administrativas y lo que pretende es crear y poner en favor de todas las personas una vía judicial específica, sumaria y preferente, con objetivos y fines también específicos, no existe fundamento para enervar la procedencia de esta última por la presencia de aquéllas, que sólo son vías específicas. Por el contrario, el juez que conoce de la tutela puede ordenar a dichos funcionarios, con todo el carácter y la fuerza de una decisión judicial de inmediato cumplimiento, que con sus recursos y capacidades hagan viable y efectiva en un caso concreto la protección de aquellos derechos constitucionales que se hallan amenazados o vulnerados por la acción de un particular.

\section{Obiter Dictum}


Vol. 6, No. 1 Diciembre de 2014 pp. $89-120$

De igual manera como se ha expuesto en las Sentencias anteriores, el Obiter Dictum hace referencia a aquellos alegatos expuestos en la parte considerativa de una Sentencia o Resolución judicial que corroboran la decisión principal, pero carecen de poder vinculante, pues su naturaleza es meramente complementaria.

Es el mismo juez el que opina o da su punto de vista jurídico acerca de un tema específico, y es esta opinión la que más tarde se puede tomar como válida para el uso en un proceso judicial, pero nunca tendrá valor de ley.

En la sentencia citada el juez invoca un punto de vista jurídico el cual contrapone el problema de agresiones contra la demandante y sus intereses de derecho de vivir en la casa. La indefensión en el presente caso debe analizarse, desde luego, en el marco de la convivencia, ya de diecisiete años, entre la demandante y su agresor. Si bien es cierto que podría ella liberarse de estar expuesta en forma permanente a los malos tratos poniendo fin a la vida en común, no puede señalarse ésta como una salida eficiente dentro del contexto sociológico en medio del cual se mueve la pareja y consideradas las circunstancias de hecho que condicionan el desarrollo de su actividad.

De las declaraciones rendidas por la accionante se colige que ella considera tener derecho a permanecer en la sede del hogar y, a juicio de la Corte, esa prerrogativa no se le puede desconocer a la luz del Sistema Jurídico colombiano. Pero, además, su convicción es la de que está obligada a sostener la relación en bien de la familia, aunque exige que, sobre esa base, le sean respetados sus mínimos derechos. Es esto es precisamente lo que la Constitución le garantiza y para lograrlo no hay necesidad de acudir a la extinción de los vínculos familiares.

La Corte estima que, mirada la situación desde el punto de vista fáctico, se tiene un verdadero estado de indefensión que hace viable la tutela, por cuanto en 


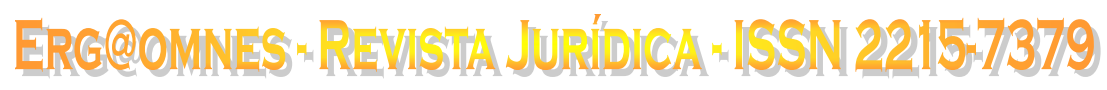

Vol. 6, No. 1 Diciembre de 2014 pp. $89-120$

el ámbito hogareño la quejosa está a merced de la fuerza física y la voluntad del varón, quien abusa de sus ventajas para ofenderla y maltratarla.

La Corte analiza que la protección judicial efectiva resulta en muchas ocasiones equivocada respecto a las lesiones personales, ya que teniendo en cuenta la pena siempre será posterior al ilícito.

Ahora bien, el criterio según el cual la peticionaria goza de otro medio de defensa judicial por cuanto está en posición de iniciar un proceso penal contra su compañero permanente por las lesiones personales que le cause, resulta ser equivocado desde el punto de vista de la protección judicial efectiva de las garantías constitucionales, teniendo en cuenta que la pena siempre será posterior al ilícito y que con su imposición no se remedia el perjuicio ya causado. En tal sentido, someter a la persona a la exigencia de nuevos daños a su integridad personal para alcanzar la protección del juez implica contrariar el sentido de amparo eficaz de los derechos en que se inspira la Constitución. Los antecedentes del caso dan lugar a que la afectada tema fundadamente que será atacada de nuevo, lo cual significa que hay amenaza verdadera, inclusive contra su vida. La administración de justicia debe poder actuar con miras a evitar que los hechos conduzcan a un resultado fatal.

\section{Decisión de la Sentencia}

La Corte Constitucional genera su resolución jurídica conforme a sus valoraciones de las leyes colombianas, a sus puntos de vista jurídicos y experiencias en las diversas experiencias y resultados de otras áreas, el cual, restablece los derechos constitucionales a las víctimas, por lo que establece:

Primero. REVOCAR el fallo proferido el veintitrés de agosto del presente año por el Juzgado Sesenta y Tres Penal del Circuito de Santa Fe de Bogotá, D.C., 
mediante el cual se resolvió acerca de la acción instaurada por María Esther Moreno Ramírez contra Manuel López.

Segundo. TUTELAR los derechos a la vida y a la integridad personal de la solicitante y de sus hijas.

Tercero. ORDENAR a Manuel López abstenerse de ejecutar cualquier acto de violencia física o moral contra María Esther Moreno Ramírez o sus hijas.

Cuarto. Por intermedio del Comandante de la Policía Metropolitana de Santa Fe de Bogotá, D.C., ORDENAR a las autoridades de policía con competencia en la Calle 68J No. 18-L-71 sur, Barrio Villa Gloria Segundo Sector de Santa Fe de Bogotá, D.C., que ejerzan vigilancia permanente y cercana sobre la conducta de Manuel López, para la efectiva protección de los derechos a la vida y a la integridad personal de la señora María Esther Moreno Ramírez y de sus hijas.

Quinto. CONFIAR al Juzgado Sesenta y Tres Penal del Circuito de Santa Fe de Bogotá, D.C., el control y verificación sobre el exacto cumplimiento de este fallo.

Sexto. ADVERTIR a Manuel López que el desacato a lo resuelto en esta providencia le acarreará, cada vez que en él incurra, las sanciones establecidas en el artículo 52 del Decreto 2591 de 1991.

Séptimo. REMITIR copias del expediente y de esta providencia a la Directora del Instituto Colombiano de Bienestar Familiar, para que inicie de inmediato las diligencias tendientes a proteger a los menores que se alojan en el lugar donde cohabitan la accionante y su compañero permanente. 
Octavo. LIBRENSE las comunicaciones previstas en el Artículo 36 del Decreto 2591 de 1991.

\section{- Sentencia T- 552/94}

\section{Hechos}

Esther Cecilia Calle Hernández instaura Acción de Tutela contra su esposo Pastor Romero Bustos, con quien tiene cuatro hijos. Manifiesta la accionante que su compañero siempre se encuentra bajo los efectos del alcohol y el poco dinero que consigue para el sustento del hogar lo regala. Informa la señora que el Señor Romero frecuentemente la golpea en forma brutal, causándole lesiones y fracturas; comenta que no solo ella es objeto de malos tratos, también los hijos son golpeados por el padre, quien además utiliza un lenguaje vulgar permanentemente. De igual modo argumenta que a la hija mayor la agredió estando embarazada, a punto de hacerla abortar.

Se solicita acción de tutela para la protección de los derechos fundamentales a la vida y a la integridad personal.

\section{Ratio Decidendi}

Con relación a esta Sentencia La Corte Constitucional en términos de la Ratio Decidendi se pronuncia e indica que los maltratos físicos al cónyuge, compañero o compañera permanente implican abierta violación del derecho a la integridad personal e invoca la Constitución Política Colombiana.

Por otra parte, es evidente el daño que tales comportamientos ocasionan a la familia, factor primordial de la convivencia y elemento social de primer orden, que merece la especial protección del Estado, contemplados en los Artículos 5 y 42 de la Constitución Política, expresados en la siguiente forma por la Carta: 
Vol. 6, No. 1 Diciembre de 2014 pp. 89 - 120

"cualquier forma de violencia en la familia se considera destructiva de su armonía y unidad y será sancionada conforme a la ley". (1991)

También la Sala Constitucional se manifiesta en los derechos y protección de los niños, y cuando alguno de los cónyuges agrede al otro, se violentan los derechos constitucionales. Es claro que toda manifestación de violencia causa necesariamente un daño, casi siempre irreparable, en el seno del hogar, pues aparte de las consecuencias materiales que apareja el acto violento en lo que respecta a la integridad de las personas, lesiona gravemente la estabilidad de la familia, ocasiona rupturas entre sus miembros, interrumpe la paz y el sosiego domésticos y afecta particularmente el desarrollo sicológico de los menores, inoculando perniciosas tendencias hacia comportamientos similares. Es por ello que, a la luz de la Constitución, las relaciones familiares se basan en la igualdad de derechos y deberes de la pareja y en el respeto recíproco entre todos sus integrantes. Cualquier forma de violencia se considera destructiva de su armonía y unidad y será sancionada conforme a la ley.

Los niños, según el Artículo 44 de la Carta Magna, tienen derecho a gozar de una familia; al cuidado, el amor y la educación, y a ser protegidos contra toda expresión de violencia física o moral. Los principios constitucionales en la materia resultan flagrantemente desconocidos cuando uno de los cónyuges o compañeros permanentes ataca físicamente al otro, pues ello no sólo significa agravio - el que ya de por sí, aunque fuera puramente verbal, quebrantaría la regla del recíproco respeto que se deben los esposos-, sino que repercute en la esfera de la integridad física y moral de la persona atacada e inclusive pone en peligro su vida.

La Corte da su punto de vista jurídico conforme a la ley e indica que los jueces deben comprometerse con la Constitución y por lo tanto deben valorar y analizar con rigor el argumento de las dos partes en litigio, esto con el fin de negar o conceder un fallo de tutela. 
Si los jueces no se comprometen con la Constitución y, por tanto, hacen fracasar en la práctica los principios que la inspiran, tornando en inaplicables los mecanismos de protección de los derechos, están faltando gravemente a su juramento y traicionando los valores esenciales del orden jurídico cuya defensa se les ha confiado en esta materia.

Para esta Corte resulta inadmisible que el Juez niegue o conceda la Tutela de antemano, sin verificar ni sopesar a conciencia lo afirmado y lo acreditado por las partes. No puede resolver el fallador sin llegar a una persuasión racional y fundada sobre el trato que merece el asunto sometido a juicio, pues la decisión carece de sustento si no se la pone en relación con los hechos probados, tanto como si se la adopta de espaldas a la normativa aplicable.

\section{Obiter Dictum}

El Obiter Dictum de esta Sentencia hace referencia a aquellos argumentos expuestos en la parte considerativa de una Sentencia o Resolución judicial que corroboran la decisión principal, pero carecen de poder vinculante, pues su naturaleza es meramente complementaria. Por lo cual la corte indica respecto a las uniones maritales, sean por matrimonio o de hecho, ambos casos gozan de amparo constitucional, así preservando el valor fundamental de la familia, que es el núcleo de la sociedad. Debe advertirse que, a la luz de la Carta Magna no cabe establecer diferencias entre la familia constituida a partir de un matrimonio y la nacida de la unión libre, pues tanto la una como la otra gozan de amparo constitucional.

Por ello, el Artículo 42 del Estatuto Fundamental señala: la familia es el núcleo fundamental de la sociedad. Se constituye por vínculos naturales o jurídicos, por la decisión libre de un hombre y una mujer de contraer matrimonio o por la voluntad responsable de conformarla. La Sala también se pronuncia sobre 
Vol. 6, No. 1 Diciembre de 2014 pp. $89-120$

otras autoridades de Colombia que están en capacidad de proteger a los ciudadanos en varias áreas, al igual que declara que las autoridades de la República están instituidas para proteger a todas las personas residentes en Colombia, en su vida, honra, bienes, creencias y demás derechos y libertades, y para asegurar el cumplimiento de los deberes sociales del Estado y de los particulares.

\section{Decisión de la Sentencia}

La Corte Constitucional falla y da su veredicto, indicando que se debe revocar el Fallo del Juzgado Civil del Circuito de Cartagena y resolver la Acción de Tutela a favor de la agredida; también proteger constitucionalmente a los hijos e impone los siguientes fallos: .

Primero. REVOCAR el fallo proferido por el Juzgado Primero Civil del Circuito de Cartagena, el 9 de agosto de 1994 al resolver sobre la Acción de Tutela instaurada por Esther Cecilia Calle Hernández contra Pastor Romero Bustos.

Segundo. TUTELAR los derechos a la vida y a la integridad personal de la solicitante y de sus hijos.

Tercero. ORDENAR a Pastor Romero Bustos abstenerse de ejecutar cualquier acto de violencia física o moral contra Esther Cecilia Calle Hernández o sus hijos.

Cuarto. Por intermedio del Comandante del Departamento de Policía Bolívar, ORDENAR a las autoridades de policía con competencia en la Manzana W Lote 5, Barrio Villa Rosita de Cartagena, que ejerzan vigilancia permanente y cercana sobre la conducta de Pastor Romero Bustos, para la efectiva protección de los derechos a la vida y a la integridad personal de la señora Esther Cecilia Calle Hernández y de sus hijos. 
Quinto. CONFIAR al Juzgado Primero Civil del Circuito de Cartagena el control y verificación sobre el exacto cumplimiento de este fallo.

Sexto. ADVERTIR a Pastor Romero Bustos que el desacato a lo resuelto en esta providencia le acarreará, cada vez que en él incurra, las sanciones establecidas en el Artículo 52 del Decreto 2591 de 1991.

Séptimo.- REMITIR copias del expediente y de esta providencia a la Directora del Instituto Colombiano de Bienestar Familiar, para que inicie de inmediato las diligencias tendientes a proteger a los menores que se alojan en el lugar donde cohabitan la accionante y su compañero permanente.

Octavo.- LIBRENSE las comunicaciones previstas en el Artículo 36 del Decreto 2591 de 1991.

\section{- Sentencia T- 421/96}

\section{Hechos}

La peticionaria contrajo matrimonio con el demandado en 1980, de esta unión nacieron 3 hijos. Pasado el tiempo la Señora decidió promover la separación de bienes y liquidación de la sociedad conyugal, debido a que su esposo había dejado de cumplir las obligaciones económicas para con su hogar. Al enterarse de la Sentencia aumentó su agresividad y con ella se iniciaron los escándalos dentro del hogar; acompañados de maltrato físico constantes golpes, utilizando objetos contundentes, cables, revólver, destornilladores, con sus propias manos, la ha intentado de ahorcar, la ha intentado asfixiar, muchas veces le introduce jabones en la boca, la mete a la regadera con la ropa, la obliga a mantener relaciones sexuales delante de una hija de 8 años de edad; obliga a los hijos a que le entreguen cualquier objeto para pegarme y si ellos no lo hacen los maltrata, A parte del maltrato físico, también la maltrata psicológicamente y 
verbalmente, utilizando palabras fuertes y deshonrosas, obligando a los hijos a que insulten a la esposa y le peguen.

Se solicita Acción de Tutela para la protección de los derechos fundamentales a la vida y a la integridad personal, a la igualdad, a la intimidad y a la paz, y los derechos de sus hijos menores al libre desarrollo de la personalidad.

\section{Ratio Decidendi}

En la Ratio Decidendi manifestada en esta Sentencia, la Sala indica que las tutelas accionadas por alguna persona que se encuentre en riesgo o que sus derechos estén a punto de ser vulnerados deben proceder, y mucho mas debe acatarse la Tutela cuando el bien tutelado de un menor este en riesgo: Se ha de recordar que los menores tienen protección especial y de primera necesidad a nivel constitucional.

En desarrollo del precepto constitucional referido, el numeral $9^{\circ}$ del Artículo 42 del Decreto 2591 de 1991, establece que la Acción de Tutela procede contra acciones u omisiones de particulares cuando la solicitud se eleve para tutelar la vida o la integridad física de quien se encuentre en estado de subordinación o indefensión respecto de la persona contra quien se interpuso la tutela, presumiéndose la indefensión del menor que solicita el amparo. En relación con la situación de indefensión por causa de maltrato familiar que hace procedente la Acción de Tutela

Indica La Corte que respecto al agresor y a las valoraciones pertinentes de la conducta y violaciones de las normas jurídicas y constitucionales, este es merecedor de unas sanciones e invoca la Ley 294 de 1996, el cual, es norma para prevenir, remediar y sancionar la violencia intrafamiliar, como el caso de la sentencia expuesta. 
Estas tres pretensiones hoy en día pueden ser satisfechas a través de la acción consagrada en la Nueva ley 294 de 1996. En efecto el Artículo $5^{\circ}$ de la misma dice así:

Si el juez determina que el solicitante o un miembro del grupo familiar ha sido víctima de violencia o maltrato, emitirá mediante sentencia una medida definitiva de protección, en la cual ordenará al agresor abstenerse de realizar la conducta objeto de la queja, o cualquier conducta similar contra la persona ofendida. El juez podrá imponer, además, según el caso, las siguientes medidas: a) Ordenar al agresor el desalojo de la casa de habitación que comparte con la víctima, siempre que se hubiere probado que su presencia constituye una amenaza contra la vida, la integridad física o la salud de cualquiera de los miembros de la familia. En la misma sentencia se resolverá lo atinente a la custodia provisional, visitas y cuota alimentaria en favor de los menores y del cónyuge si hubiera obligación legal de hacerlo; b) Cuando la violencia o el maltrato revista gravedad y se tema su repetición, el juez ordenará una protección especial de la víctima por parte de las autoridades de policía, tanto en su domicilio como en su lugar de trabajo, si lo tuviere. (Colombia. Congreso de la República, 1996)

\section{Obiter Dictum}

El Obiter Dictum de esta Sentencia hace referencia a aquellos argumentos expuestos en la parte considerativa de una Sentencia o Resolución judicial que corroboran la decisión principal, pero carecen de poder vinculante, pues su naturaleza es meramente complementaria. Por lo cual, La Corte da su punto de vista e indica que las acciones policiales no tienen poder judicial, sino que es un medio de defensa para preservar el orden, a su vez como se analizó en la Sentencia anterior que es solo de función administrativas. 
En relación con las acciones policivas, también definió la jurisprudencia constitucional que éstas, por tratarse de medios de defensa que no pueden ser calificados de judiciales, no impiden el ejercicio de Acción de Tutela.

\section{Decisión de la Sentencia}

La Sala mediante su fallo, indica que se deben proteger los derechos constitucionales a las víctimas de las agresiones, respecto al derecho a la vida, a la protección, la paz y a la integridad personal, a su vez, coloca unas amonestaciones al agresor.

Primero. ADICIONAR con las siguientes decisiones la Sentencia proferida por el Tribunal Superior del Distrito Judicial de Santafé de Bogotá el dos de mayo de 1996 en el asunto de la referencia: a) CONCEDER la tutela de los derechos constitucionales fundamentales a la vida y a la integridad personal que $X X$ reclama en contra de su esposo $Y Y$. b) ORDENAR a YY abstenerse de ejecutar cualquier acto de violencia física o moral en contra de su esposa XX. c) ORDENAR por intermedio del Comandante del Departamento de Policía respectivo, a las autoridades de policía con competencia en el lugar en donde habita y labora la actora, ejercer vigilancia permanente y cercana sobre la conducta del citado YY para la efectiva protección de los derechos a la vida y a la integridad personal de XX. d) ADVERTIR a YY que el desacato a lo dispuesto en esta providencia le acarreará, cada vez que en él incurra, las sanciones establecidas en el artículo 52 del Decreto 2591 de 1991. e) CONFIAR al Juzgado Veinte de Familia de Santafé de Bogotá, velar por el estricto cumplimiento de lo dispuesto en este fallo. f) NEGAR la acción de tutela en lo referente a la segunda pretensión contenida en ella, relativa a que los hijos de la solicitante fijen su residencia en el inmueble donde siempre han vivido. 
Vol. 6, No. 1 Diciembre de 2014 pp. 89 - 120

Segundo. En lo demás CONFIRMAR el fallo proferido por el Tribunal Superior del Distrito Judicial de Santafé de Bogotá.

Tercero. ORDENAR, en guarda del derecho a la intimidad de la familia relacionada con este proceso, que en toda publicación de la presente sentencia se omitan los nombres de los menores involucrados en él.

\section{CONCLUSIONES}

La Corte Constitucional genera y estima prioridad a la protección de los derechos fundamentales constitucionales de los ciudadanos colombianos respecto a la violencia intrafamiliar de manera general y tal vez ha actuado con mucha comprensión y paciencia con los agresores, pero respecto a la violencia intrafamiliar generada específicamente por el alcoholismo y la drogadicción aún existen vacíos doctrinales que aún no han sido expuestos, ya que pueden acrecentar la responsabilidad del individuo agresor en estado de alcoholemia o drogadicción, esto con la intención de salvaguardar el derecho a la vida, el derecho a la integridad personal, el derecho a la protección y el derecho a la paz, derechos que son de carácter constitucional como los que se establecen en los Artículos 11, 12, 21, 22 y 86 de la Constitución Política.

Ahora, cuando un individuo pone en riesgo los derechos constitucionales de las demás personas a través de la adicción del alcohol o las drogas, en este caso los miembros de su propia familia, la justicia debe actuar de inmediato antes que los derechos mencionados anteriormente sean vulnerados y la violencia intrafamiliar llegue hasta el punto de convertirse en un tipo de delito penal. En cuanto al agresor adicto al alcohol o a las drogas, la Corte Constitucional indica que requiere de un tratamiento especial ya que su actuar o comportamiento es el resultado de un deseo repetido: 
El alcoholismo presenta, desde el punto de vista jurídico, varias características relevantes y concurrentes: i) se trata de una afección que es el resultado del deseo repetido de quien consume alcohol, es decir, el alcoholismo no surge instantáneamente sino que su desarrollo supone una conducta continuada en el tiempo; ii) el consumo de alcohol puede generar cambios profundos en el comportamiento de la persona. (Colombia. Corte Constitucional, 2001)

Debería ser todo lo contrario, no ser tratado de manera especial en ciertos aspectos, ya que el agresor bajo los efectos del alcohol o de las drogas incrementa su violencia y se aparta de la realidad. También manifiesta que el órgano policivo si bien es cierto debe vigilar y controlar el comportamiento social, este no puede obrar como un organismo judicial independiente, no puede imponer penas ni sanciones ya que su ejercicio es solo administrativo y que solo debe actuar cuando la justicia se lo demande mediante órdenes. Con relación a los Jueces de primera y segunda instancia que reciben las tutelas que invocan la protección constitucional o que está en peligro el bien jurídico tutelado, estos deben revisar correctamente el caso y sopesar el juicio de razón de las dos partes involucradas en el conflicto respecto a las leyes, con el fin de conceder o negar la tutela.

Finalmente se evidencia que aun hace falta legislar o sentenciar problemas relacionados con la violencia intrafamiliar generados por el alcohol y las drogas, ya que se vulneran derechos constitucionales, si se observan los detalles de las Sentencias analizadas, solo una hace referencia al tema que se estudió, la Sentencia T-133 de 2004. 


\section{BIBLIOGRAFÍA}

Bernal C. (2006). Metodología de la investigación. México: Pearson Educación

Congreso de Colombia. (2000). LEY 599 DE 2000. Octubre 15 de 2014, de Diario

Oficial No. 44.097 de 24 de julio del 2000

Sitio web:

http://www.secretariasenado.gov.co/senado/basedoc/ley_0599_2000.html\#1

Colombia. Asamblea Nacional Constituyente. (1991). Constitución Política de Colombia de 1991. Bogotá: Editorial Panamericana.

Colombia. Código Penal Colombiano. Editorial Unión Ltda.

Colombia. Corte Constitucional. (1992). Sentencia T-529 de Septiembre 4 de 1992. No. expediente T-2710.

Colombia. Corte Constitucional. (2004). Sentencia T-133 de febrero 18 de 2004.No. expediente T-825738.

Colombia. Corte Constitucional. (1994). Sentencia T-487 de Noviembre 2 de 1994. Expediente T-46268.

Colombia. Corte Constitucional. (1994). Sentencia T-552 de Diciembre 2 de 1994. Expediente T-46517.

Colombia. Corte Constitucional. (1996). Sentencia T-421 de Septiembre 9 de 1996. Expediente T-97837.

Colombia. Corte Constitucional. (2001). Sentencia T-1325 de Diciembre 7 de 2001. Expediente T-464034. 


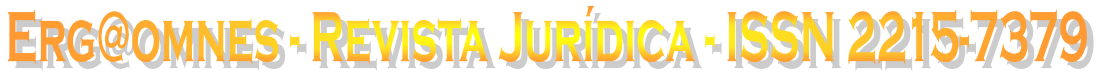

Vol. 6, No. 1 Diciembre de 2014 pp. 89 - 120

López. D. (2006). El derecho de los jueces. Bogotá: Legis

Iriarte M., F. (1997). Diccionario Jurídico Básico. 2ª . Ed. S.C.: Ediciones Esquilo. 